\title{
Utility of the Morisky Medication Adherence Scale in gout: a prospective study [Corrigendum]
}

Tan CSL, Teng GG, Chong KJ, et al. Patient Prefer Adherence. 2016;10:2249-2457.

On page 2452, Table 2, the copyright statement "Use of the CMMAS is protected by US copyright laws. Permission for use is required. A license agreement is available from: Donald E. Morisky, 14725 NE 20th St Bellevue, WA 98007 , USA; dmorisky@gmail.com.9,53,54" was not included in the Note section.

On page 2450, under "Medication adherence measures" section: the entire first paragraph should be removed. The paragraph should be replaced with: "Self-reported medication adherence was measured by the MMAS- $8.9,53,54$ The MMAS- 8 scale consists of eight items of which summation yields a maximum of 8 points. The result is categorized into 3 groups to reflect low, medium and high adherence. ${ }^{9,53,54 \text {, }}$

On page 2455, “Acknowledgment section", the acknowledgment was "MMAS-8 license fee was supported by Dr Gim Gee Teng's Indirect Research Cost account (NDRF3020070I), which is a cumulative general purpose fund that holds the Principal Investigator's share of the Indirect Research Cost levied on grantors. Use of this fund is subject to institution guidelines on payable items. We acknowledge the kind permission obtained from Takeda Pharmaceuticals in May 2009 to use the GAQ 2.0 in Singapore. Registration of research for use of EuroQoL-5 dimension 3 levels (EQ5D) was obtained on 10 September 2014." However it should have been "We thank Professor Donald E Morisky, Department of Community Health Sciences, UCLA Fielding School of Public Health, Los Angeles, United States, for granting them the use of the copyrighted MMAS-8. Professor Morisky has worked his entire career in developing the very important instrument for medication-taking behavior measure. Use of the CMMAS is protected by US copyright laws. Permission for use is required. A license agreement is available from: Donald E. Morisky, 14725 NE 20th St Bellevue, WA 98007, USA; dmorisky@gmail.com. The MMAS-8 license fee was supported by Dr Gim Gee Teng's Indirect Research Cost account (NDRF3020070I), which is a cumulative general purpose fund that holds the Principal Investigator's share of the Indirect Research Cost levied on grantors. Use of this fund is subject to institution guidelines on payable items. We acknowledge the kind permission obtained from Takeda Pharmaceuticals in May 2009 to use the GAQ 2.0 in Singapore. Registration of research for use of EuroQoL-5 dimension 3 levels (EQ5D) was obtained on 10 September 2014".

On page 2456, "References", these references should be included:

53. Krousel-Wood MA, Islam T, Webber LS, Re RS, Morisky DE, Muntner P. New Medication Adherence Scale Versus Pharmacy Fill Rates in Seniors with Hypertension. Am J Manag Care. 2009;15(1): 59-66

54. Morisky DE, DiMatteo MR. Improving the measurement of selfreported medication nonadherence: Final response. J Clin Epidemio. 2011;64(3):258-263.
Patient Preference and Adherence

\section{Publish your work in this journal}

Patient Preference and Adherence is an international, peer-reviewed, open access journal that focuses on the growing importance of patient preference and adherence throughout the therapeutic continuum. Patient satisfaction, acceptability, quality of life, compliance, persistence and their role in developing new therapeutic modalities and compounds to optimize

\section{Dovepress}

clinical outcomes for existing disease states are major areas of interest for the journal. This journal has been accepted for indexing on PubMed Central. The manuscript management system is completely online and includes a very quick and fair peer-review system, which is all easy to use. Visit http://www. dovepress.com/testimonials.php to read real quotes from published authors. 